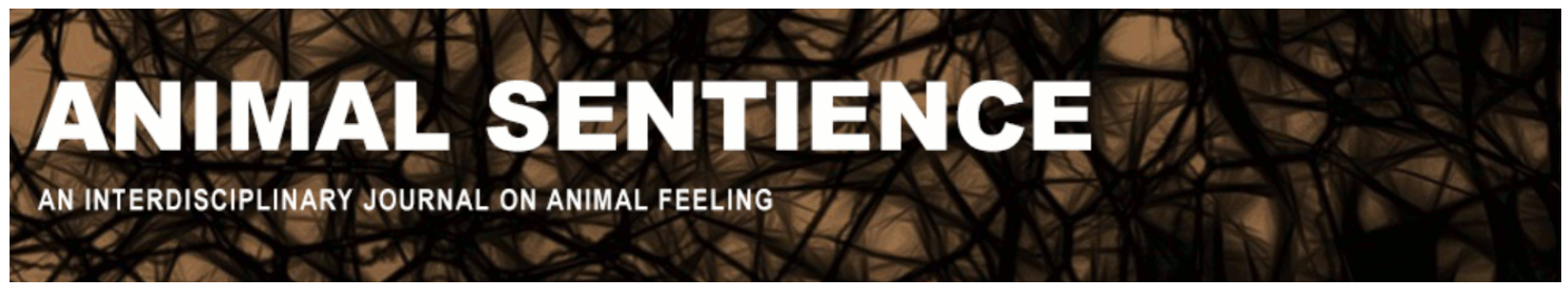

Figdor, Carrie (2019) The mental lives of sheep and the quest for a psychological taxonomy. Animal Sentience 25(16)

DOI: $10.51291 / 2377-7478.1449$

Date of submission: 2019-05-19

Date of acceptance: 2019-05-24

(c)

This article has appeared in the journal Animal

Sentience, a peer-reviewed journal on animal

cognition and feeling. It has been made open access,

free for all, by WellBeing International and deposited

in the WBI Studies Repository. For more information,

please contact

wbisr-info@wellbeingintl.org.

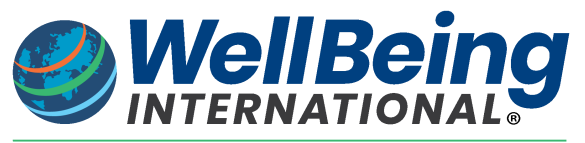

SOLUTIONS FOR PEOPLE, ANIMALS AND ENVIRONMENT 


\title{
The mental lives of sheep and the quest for a psychological taxonomy
}

\author{
Commentary on Marino \& Merskin on Sheep Complexity
}

\author{
Carrie Figdor \\ Departments of Philosophy and Psychological \& Brain Sciences \\ University of lowa
}

\begin{abstract}
Research into nonhuman cognition has broadened and deepened in recent years. It supports and motivates a shift toward an ecological rather than an anthropocentric approach to cognition.
\end{abstract}

\begin{abstract}
Carrie Figdor is Associate Professor in the Department of Philosophy, Department of Psychological \& Brain Sciences, and the Neuroscience Institute, University of lowa. Her main research is in philosophy of psychology and neuroscience. Website
\end{abstract}

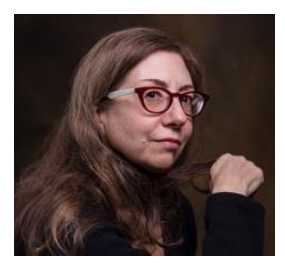

Marino \& Merskin's (2019) (M\&M) review of the empirical literature on sheep cognition should be understood in the context of two developments in psychology: (1) the enormous and growing body of research into nonhuman cognition and (2) the resulting theoretical shift towards a nonanthropocentric psychological taxonomy. I will focus on (2), following a few remarks on (1).

M\&M have added sheep to the list of nonhuman, nonprimate biological species whose cognitive capacities are being explored (e.g., slime moulds, plants, bacteria, corvids, cephalopods, cetaceans, etc.). Shettleworth's (1993) complaint that there wasn't much "comparative" in "comparative cognition" is being addressed in spectacular fashion in new species, newly developed species-appropriate experimental paradigms, and field work. As Adolphs (2019) notes, neural and modeling data should be added to the behavioral data to establish the presence of cognitive capacities (more on this below). Peña-Guzmán (2019) and Vonk (2019) raise two big reasons for caution regarding this research: inferences to the capacities of whole species from small nonrandom samples of individuals, and overinterpretation of behavioral data in terms of latent cognitive constructs. Such skepticism is warranted to avoid reading into the data what may not be there. We have no idea what the distribution of a given capacity might be within a species, and concerns about anthropomorphizing are not idle. However, the fact that both concerns arise is a clear indicator of a shift in thinking about the extent of mind in nature, from a humans-only prerogative to a widespread feature of evolved systems.

This shift is the theoretical aspect indicated above, which is motivated and supported by the research M\&M review. The theoretical goal is not merely better understanding of what individual species can do. It is a psychology in which cognitive capacities are classified within a comprehensive structure that provides an overall understanding of the mind in nature. We are struggling to abandon the anthropocentric program criticized by Shettleworth in 1993, which can be conceptualized as a continuum (a psychological Great Chain of Being) with human cognition as its supreme expression anchoring one end, or as a single-hub network with human cognition 
at the center. Instead, we are forming a hierarchical structure for psychology similar to that of the taxa or clades of biology. This is a structure that can realize what Shettleworth $(1993 ; 2009)$ dubbed the ecological program, where we ask what capacities species have developed to flourish in their niches, not whether they can do something that approximates what humans can do (setting them up for failure). Independent development of the same advanced capacities in at least some cephalopods (see Mather 2019) already guarantees that the biological and emerging psychological taxonomies will stand in a complicated relationship. However, these structures will look far more similar than the biological and anthropocentric psychological structures now do.

This overarching theoretical project is advancing in fits and starts. An example is the way the so-called mirror test became the benchmark for self-recognition. It is a test designed for humans, as we are a visual species familiar with mirrors. Other species can pass the mirror test too, but it is hardly appropriate for species that depend on olfaction or audition (e.g., Cazzolla Gatti 2015). Yet the more the species that pass species-appropriate tests, the more the concept of "self" measured by such tests will come under sustained scrutiny. A concept already under such scrutiny is episodic memory. It was introduced by Tulving as recalling what, where, and when something occurred as well as conscious recollection of the event. Clayton et al. (2007) and Allen and Fortin (2013) argue that the requirement of conscious recollection as reported by verbal behavior, which was characteristic of Tulving's human subjects, is not merely inappropriate for animals: We do not (yet?) have agreed-upon indicators of consciousness in nonhumans. Hence to include verbally reportable consciousness in the definition of episodic memory rules out the possibility of a nonhuman counterpart a priori.

The online Cognitive Atlas provides the start of a psychological taxonomy that systematizes psychological concepts and their relationships, but it is based on human studies ( $\mathrm{fMRI}$ results and their associated tasks). Following Tulving, it defines episodic memory partly in terms of what can be explicitly stated, and categorizes it as a form of consciousness. As Adolphs urges, further anatomical and physiological research, including $\mathrm{fMRI}$ studies with nonhumans, is needed, although neuroscience is not immune to anthropocentrism (Parvizi 2009). These efforts must be seen as contributions to the development of a modern system of classification of psychological constructs that are non-anthropocentrically defined and based on evolutionary biological relationships, habitat similarities, mathematical and computational modeling, as well as natural and experimentally induced behavior, all approached from a cross-species perspective.

I have argued for recognition of this ongoing conceptual and structural revision elsewhere (Figdor 2018). Non-anthropocentric psychology is a work in progress, but what is already clear is that it will not justify our current moral taxonomy, where supreme human moral value corresponds to human psychological superiority and centrality (cf. Chapman \& Huffman 2018). Unfortunately, our moral schema is not yet adjusting to these shifts in psychology. Domesticated sheep are a poster case of a species that deserves better treatment but is unlikely to get it very soon. We are highly motivated to maintain our superior moral status and the privileged treatment it affords to all humans over all nonhumans, and we have the cognitive tools to maintain that status in the face of unwelcome empirical evidence (e.g., Bastian et al. 2012). In the longer term, however, we may be forced to acknowledge that we aren't at the center of the moral universe - or at least not there alone - any more than we are at the center of the psychological universe. That is a conceptual (and affective) change that empirical evidence alone will not induce. 


\section{References}

Adolphs, R. 2019. Using sheep psychology to guide sheep policy. Animal Sentience 25(14) Allen, T. and N. Fortin 2013. The evolution of episodic memory. PNAS 110 (2): 10379-86. Bastian, B., S. Loughnan, N. Haslam and H. Radke. 2012. Don't mind meat? The denial of mind to animals used for human consumption. Personality and Social Psychology Bulletin 38 (2): 247-56.

Cazzolla Gatti, R. 2015. Self-consciousness: beyond the looking glass and what dogs found there. Ethology, Ecology \& Evolution 28 (2): 232-40.

Chapman, C. A. and M. A. Huffman. 2018. Why do we want to think humans are different? Animal Sentience 23(1)

Clayton, N., L. Salwiszek, and A. Dickinson. 2007. Episodic memory. Current Biology 17 (6): R189-91.

Figdor, C. 2018. Pieces of mind: The proper domain of psychological predicates. Oxford.

Marino, L. and D. Merskin. 2019. Intelligence, complexity, and individuality in sheep. Animal Sentience 25(1)

Mather, J. 2019. What is in an octopus's mind? Animal Sentience 26(1)

Parvizi, J. 2009. Corticocentric myopia: old bias in new cognitive sciences. Trends in Cognitive Sciences 13 (8): 354-59.

Peña-Guzmán, D. 2019. Casting a sheep's eye on science. Animal Sentience 25(6)

Shettleworth, S. 1993. Where is the comparison in comparative psychology? Psychological Science 4 (3): 179-84.

Shettleworth, S. 2009. The evolution of comparative cognition: Is the snark still a boojum? Behavioural Processes 80: 210-17.

Vonk, J. 2019. Pulling the wool from our eyes. Animal Sentience 25(3) 